\title{
Para além da punição: (re)construindo o conceito de responsabilização socioeducativa
}

\section{Going beyond the punishment: (re)building the responsibility socioeducacional concept}

\section{Más allá de la sanción: (re)construyendo el concepto de responsabilidad socioeducacional}

\author{
Fernanda Pinheiro Rebouças Valente* \\ Universidade de Brasília - UnB, Brasília, Distrito Federal, Brasil \\ Maria Cláudia Santos Lopes de Oliveira** \\ Universidade de Brasília - UnB, Brasília, Distrito Federal, Brasil
}

\begin{abstract}
RESUMO
O presente artigo discute o conceito de responsabilização juvenil, a partir do Estatuto da Criança e do Adolescente (ECA), da Lei 12.594 que institui o Sistema Nacional de Atendimento Socioeducativo e da filosofia, e considera os impactos da polissemia do termo sobre a apropriação que dele fazem os operadores do sistema socioeducativo. Os documentos normativos fazem menção a diferentes formas de responsabilização, vistas como alternativas não punitivas no processo socioeducativo, sem que apresentem uma definição clara desses termos. A imprecisão do conceito pode estar contribuindo, no processo histórico, para a manutenção do caráter coercivo, aflitivo e punitivo, frequentemente presentes na execução de medidas socioeducativas. Para chegar a uma compreensão mais clara da questão, procedeu-se inicialmente a análise documental de textos legais que tratam do processo de responsabilização socioeducativa. No segundo momento, realizou-se pesquisa quali-quantitativa, em que um instrumento do tipo escala Lickert foi aplicado entre operadores do sistema socioeducativo. Os resultados evidenciam que a vinculação entre punição e culpabilização e as práticas promotoras de responsabilização socioeducativa, diz mais sobre as crenças e as representações que seguem existindo dentro do sistema socioeducativo do que a um não conhecimento das leis e normas que regem o sistema socioeducativo pelos profissionais.
\end{abstract}

Palavras-chave: responsabilização, socioeducação, responsabilidade socioeducativa.

\footnotetext{
ABSTRACT

This article discusses the concept of juvenile responsibility, from the Child and Adolescent Statute, the Law no. 12594, which established the National System of Socioeducational Care and the philosophy. Normative documents mention the different forms of responsibility, seen as non-punitive alternatives in socioeducational process without presenting a clear definition of these terms. The vagueness of the concept may be contributing, in the
} 
historical process, to maintain the coercive character, distressing and punitive, often present in the execution of educational measures. To get a clearer understanding of the issue, we proceeded initially desk review of legal texts that address the socio responsibility process. In the second phase, there was qualitative and quantitative research, in which a scale Likert type instrument was applyto theprofessionals of the teen care system. The results show that the link between punishment, guilt and practices that promote socio responsibility, says more about the ideologies and representations continue to exist within the childcare system to a nonknowledge of the laws and regulations governing childcare system by professionals.

Keywords: responsibility, socioeducasional care, socioeducasional responsibility.

\begin{abstract}
RESUMEN
Este artículo aborda el concepto de responsabilidad juvenil, del Estatuto del Niño y del Adolescente, la Ley 12.594 establece el Sistema Nacional de Servicios y la filosofía socio-educativo, y considera que la polisemia plazo de los impactos sobre la apropiación incluido en el mismo la los operadores de sistemas de cuidado de los niños. Documentos normativos mencionan las diferentes formas de rendición de cuentas, vistos como alternativas no punitivas en proceso socio-educativo sin presentar una clara definición de estos términos. La vaguedad del concepto puede estar contribuyendo, en el proceso histórico, para mantener el carácter coercitivo, angustiante y punitiva, a menudo presente en la ejecución de medidas educativas. Para obtener una comprensión más clara de la cuestión, se procedió inicialmente examen teórico de los textos legales que abordan el proceso de responsabilidad socio. En la segunda fase, hubo una investigación cualitativa y cuantitativa, en la que se aplicó un instrumento tipo Likert de escala entre los operadores del sistema de cuidado de niños. Los resultados muestran que el vínculo entre el castigo y la culpa y prácticas que promueven la responsabilidad socio, dice más acerca de las ideologías y representaciones siguen existiendo en el sistema de cuidado de niños a un no-conocimiento de las leyes y reglamentos que rigen el sistema de cuidado de niños profesionales.
\end{abstract}

Palabras clave: responsabilidade, socioeducation, responsabilidad socioeducativa.

\title{
1 Introdução
}

O presente artigo tem como objetivo refletir sobre o conceito de responsabilização juvenil. Trata-se de um recorte de uma pesquisa empírica, intitulada O Processo de Responsabilização Socioeducativo: Da medida à Responsabilidade, que visa investigar as concepções sobre responsabilização encontradas no sistema socioeducativo e como elas se expressam em perspectivas de atendimento ao adolescente autor de ato infracional.

Como forma de conseguir melhor compreensão sobre o processo de responsabilização socioeducativo, foi feita análise documental em textos normativos e não normativos da área. Entre os documentos normativos considerados estão: Estatuto da Criança e do Adolescente 
(ECA); Res. 119/2006 (Conanda), que institui o Sistema Nacional de Atendimento Socioeducativo (SINASE); Lei 12.594 que institui o Sistema Nacional de Atendimento Socioeducativo (SINASE); Plano Nacional de Atendimento Socioeducativo (Resolução 160/2013 do Conanda); Documentos complementares da Secretaria de Direitos Humanos da Presidência da República (SDH), Conselho Nacional dos Direitos da Criança e do Adolescente (CONANDA). E entre os não normativos foram considerados artigos, dissertações e teses de diferentes campos disciplinares que tratavam sobre o tema da responsabilização e da socioeducação.

A técnica de análise documental propõe que a base de dados a ser analisada siga critérios de credibilidade, representatividade e significação em relação ao tema que se visa aprofundar (Flick, 1995/2009). Desse modo os textos já mencionados foram selecionados por constituírem "dispositivos comunicativos metodologicamente desenvolvidos na construção de versões sobre eventos" (Flick, 1995/2009, p. 234), portanto, ferramentas importantes de contextualização de concepções legais, filosóficas, científicas e sociais sobre o tema da responsabilização no sistema socioeducativo.

\section{0 processo de responsabilização e o sistema socioeducativo}

Apesar de sua relevância para o estabelecimento de diretrizes no trabalho socioeducativo, existe pouca literatura sobre o conceito de responsabilidade e responsabilização na socioeducação. Até mesmo no ECA e no SINASE esses termos aparecem sem consistência conceitual e, na maioria das vezes, empregados em função da responsabilidade parental ou estatal sobre a criança e o adolescente. Esse fato pode justificar a dificuldade, tanto para os teóricos da área como para os operadores do sistema socioeducativo, de diferenciar o conceito de responsabilização penal do conceito de responsabilização vinculado aos direitos humanos, à educação e à cidadania, defendido na socioeducação. Dessa forma, a ambiguidade jurídica referente à polissemia do termo responsabilização, pode estar culminando na ambiguidade prática das ações socioeducativas.

O tema da responsabilidade, ao longo da história, foi estudado por inúmeros filósofos, entre eles: Heidegger, Sartre, Nietzsche, Lévinas, Kant e Bakhtin. Neste artigo será focado nas contribuições dos dois últimos citados, por acreditar-se que eles representam de maneira mais clara as principais ideologias normativas (Kant) e não normativas (Bakhtin) que embasam as discussões sobre o processo de responsabilização na contemporaneidade.

Para Kant, o tema da responsabilidade emerge no campo da moral e corresponde a um imperativo que leva o sujeito a agir de modo que a 
liberdade esteja condicionada ao imperativo ético, ao agir desinteressado, movido pela vontade pura e orientado à obrigação moral do bem agir (Meneses \& Reis, 2009). Nessa perspectiva, o agir responsável é atributo individual pautado em parâmetros universais. É atributo que vem unicamente da lei, do dever agir de acordo com essa lei. A atividade moral, para Kant, então, não deve ser "instigada por outra inclinação a não ser o respeito à lei" (Meneses \& Reis, p. 105) sendo, por isso, universal para todos os seres humanos.

De modo diverso, encontram-se em filósofos como Bakhtin as bases para a concepção dialógica de responsabilidade, interdependente da alteridade, na qual a responsabilidade envolve o comprometimento prioritariamente voltado ao outro. Na obra Para uma Filosofia do Ato (1924/2010), Bakhtin indica que a responsabilidade estaria ligada ao pensamento participativo, sendo "a fundação da ação moral, o modo pelo qual nós superamos a culpa da cisão entre nossas palavras e nossas ações" (p. 9). Destaca-se, com isso, a importância da autorreflexão e da participação - comprometida como ação negociada com o outro - para o processo de responsabilização.

Dessa forma, apesar de tanto Kant como Bakhtin terem seguidos princípios morais gerais, na teoria de Bakhtin tais princípios adquirem sentido contextual que se centra nos sujeitos concretos, sem corresponder necessariamente à universalidade. Por isso, a responsabilidade/responsividade, segundo a teoria de Bakhtin, está situada na valoração/avaliação que o sujeito faz sobre seus próprios atos, sendo um princípio unificador de todo o agir. Na obra de Bakhtin, o valor do ato é o valor que ele tem para o agente em suas interações com o mundo e não, simplesmente, um valor absoluto que seria imposto a ele pelos outros (Sobral, 2009).

É importante salientar que a participação ativa, comprometida e reflexiva dos adolescentes, seguindo a lógica bakhtiniana, é essencial para o processo de responsabilização. Além disto, a política éticopedagógica proposta pela Lei Nacional do Sistema Socioeducativo (SINASE) dá destaque à participação da comunidade e da família no processo de responsabilização do adolescente, distanciando-se da proposta Kantiana da responsabilização puramente individual e aproximando-se da proposta de corresponsabilização, em que o adolescente, o Estado, a família e a sociedade podem e devem colaborar (Aguinsky \& Capitão, 2008).

A ênfase sobre a corresponsabilidade como eixo do processo de responsabilização socioeducativa não exime o adolescente de sua responsabilidade individual. Acredita-se que as escolhas individuais realizadas de acordo com padrões e limites condicionados pelos processos de construção sócio-histórica do sujeito estabelecem que cada um seja o principal agente de mudança e de transformação de sua própria história (Sifuentes, Dessen, \& Lopes de Oliveira, 2007). Por isso, o adolescente deverá ter participação ativa em todo o 
processo socioeducativo. Afinal, como destacou Sobral (2009) sobre a responsabilidade defendida por Bakhtin.

O termo "responsabilidade" une o responder pelos próprios atos, o responder por, e a responsividade, o responder a alguém ou a alguma coisa, sendo fiel à palavra russa otvetstvennost', que designa o aspecto responsivo e o da assunção de responsabilidade do agente pelo seu ato. $O$ ato "responsável" envolve o conteúdo do ato, seu processo, e, unindo-os, a valoração/avaliação do agente com respeito a seu próprio ato (p. 124).

Dessa forma, Bakhtin, diferentemente de Kant, valoriza a singularidade de cada sujeito, percebendo a responsabilidade como noção que não se volta unicamente para problemas gerais através dos quais é abstraído o particular, mas como relação entre o pensamento participativo e o dialogismo em suas diversas dimensões. Inclui-se nesse sentido de dialogismo a relação com o outro, a presença e a valorização constante da alteridade na qual será constituído o "eu" e o autorreconhecimento do sujeito (Nuto, 2011).

Por isso, o tema da responsabilização socioeducativa pode se tornar problemático quando a responsabilização é limitada à atribuição de responsabilidade pelo outro (juiz) e não possibilita a emergência no adolescente de posicionamentos responsáveis. Essa questão reflete um conjunto de tensões que permeiam o atendimento socioeducativo e que se materializam nas discussões entre práticas tutelares e as promotoras de autonomia; sobre o tênue limiar que divide os direitos civis dos direitos sociais, bem como, das diferenças legais, muitas vezes negadas na prática, entre o sistema de justiça penal e o sistema de justiça socioeducativo (Vicentin, 2006; Vicentin, Borghi \& Rosa, 2012).

Além desses pontos mencionados, outro aspecto digno de reflexão, no que se refere ao tema da responsabilização dos adolescentes, está relacionado à polissemia do próprio termo responsabilização e à tendência de se reificar alguns conceitos que são incorporados ao texto das leis, ignorando-se as bases ideológicas, políticas ou científicas que lhes deram origem. Desse modo, os parâmetros e bases conceituais que permitiriam discutir ou qualificar as práticas de responsabilização não punitivas podem estar sendo desconsideradas pelos atores do processo socioeducativo, favorecendo a reprodução das identificações entre o sistema penal e o sistema socioeducativo (Frasseto, 2006; Nicodemos, 2006; Ramidoff, 2011; Vincentin, 2006). Segundo Nicodemos (2006), "quando tratamos da questão do adolescente autor de ato infracional, antecipadamente remetemos 0 problema para um sistema de controle penal" (p. 65), e, como tal, 
acaba-se prezando a punição, a dor, o sacrifício daquele que deve ser responsabilizado, independentemente se ele é adolescente ou adulto. Seguindo-se os princípios do ECA e do SINASE, a socioeducação deveria se caracterizar pela perspectiva restaurativa. Contudo, ao se imiscuir na lógica inerente ao sistema penal, ela assume foco retributivo e meramente sancionatório. A infração é, então, vista como violação à lei, na qual o agente deve ser individualmente responsabilizado, e a medida socioeducativa, para ser eficiente, deve impor sofrimento, no intuito de bem coibir e prevenir futuros atos. Esse fato pode ser justificado pela sociedade, de modo geral, não reconhecer em formas de intervenção socioeducativas menos invasivas a possibilidade de promover a responsabilização efetiva (Frasseto, 2006; Nicodemos, 2006; Ramidoff, 2011; Vincentin, 2006). Por isso, a responsabilização jurídica é acionada como a principal estratégia de responsabilização, seja no meio socioeducativo ou no meio penal.

Segundo Brayner de Farias (2012), é a responsabilização jurídica que possibilita a vida social: É necessário que as pessoas respondam por seus atos, visto que eles podem causar danos aos outros e ao meio. Quando o foco da justiça juvenil incide exclusivamente na responsabilização jurídica, aquela pode ser compreendida como resposta que visa atender à necessidade de punir o adolescente aos olhos da sociedade. A ideia da ação com caráter pedagógico que possibilite seu desenvolvimento e novas trajetórias de vida, deixa de ser uma finalidade. Ao contrário, há radicalização da cultura punitiva, em que a aplicação da medida socioeducativa rígida aparece como a única alternativa aceita pela sociedade para o combate à violência, à insegurança e à desigualdade social (Vincetin et al., 2012).

Em contrapartida, o sistema socioeducativo, de acordo com a norma estatutária, deveria ser embasado em métodos pedagógicos que objetivassem uma responsabilização cidadã. $O$ processo de responsabilização dos adolescentes deveria ser visto não apenas como um aspecto meramente jurídico, mas, também, como forma de atenção ao ser humano que visasse contribuir para um projeto de vida responsável (Ramidoff, 2011). Esse posicionamento estaria em acordo com a concepção de adolescente como sujeito historicamente inacabado, que deve ser responsabilizado tendo em conta exclusivamente 0 ato que praticou. A responsabilização, com isso, não deveria se confundir com a situação socioeconômica e política que o autor da infração ocupa, na visão de um Estado que muitas vezes se torna criminalizador e criminalizante (Nicodemos, 2006). É nessa perspectiva de se alcançar um atendimento socioeducativo mais humanizado e promotor de desenvolvimento, que é possível vislumbrar outras formas de responsabilização, menos punitivas e mais pedagógicas. 
Por exemplo, a responsabilização individual, como o nome já sugere, estaria relacionada ao processo subjetivo e pessoal de tomada de consciência pelo adolescente. Teria, com isso, pouca relação com a medida socioeducativa determinada a ele pelo juiz e dependeria, de forma mais enfática, do processo de autorreconhecimento do adolescente como sujeito. Como defende Bakhtin, a responsabilização individual só acontece por meio de processo reflexivo e dialógico no qual o adolescente se reconhece como fazendo parte de uma sociedade que tem valores e princípios morais historicamente construídos. Envolve, necessariamente, a compreensão de que toda ação individual é um elo na cadeia de ações sociais que têm, portanto, impactos em outro indivíduo. Desse modo, a responsabilização individual estaria vinculada ao sentimento de pertencimento a um contexto sociocultural e não deveria se confundir com a mera expressão de uma imposição arbitrária da sociedade (Vicentin et al., 2012).

Pelo que foi exposto, é possível perceber que não há responsabilização individual sem que haja prévia responsabilização social, visto que o processo de responsabilização pretendido na socioeducação perpassa aspectos inerentes à reciprocidade social e à perspectiva de cidadania. Por isso Vicentin et al., (2012) argumentam que:

O sistema de responsabilização do jovem autor de ato infracional deve incluir a compreensão de que o convívio social exige reciprocidade. $O$ adolescente que não participa da construção de normas coletivas e não tem confirmado que o Estado e os adultos respeitam seus direitos e cumprem suas obrigações dificilmente compreenderá e respeitará o código que rege as relações sociais (p.275).

Ademais, uma das contribuições conceituais que o SINASE trouxe a respeito do processo de responsabilização materializa-se no conceito de corresponsabilidade. Extraído dos pilares da justiça restaurativa que, segundo Aguisnky (2007), caracteriza-se como "um novo modelo de justiça que assume as relações prejudicadas por situações de violência como preocupação central e que se orienta pelas consequências e danos causados e não pela definição de culpados e punições" (2007, p. 1). A justiça restaurativa almeja modificar o tratamento destinado ao ato infracional, possibilitando novas estratégias de intervenções, voltadas para a transformação social.

Por isso, pode-se dizer que o conceito de corresponsabilidade, criado pela justiça restaurativa, integra, em certa medida, todas as formas de responsabilização já apresentadas em uma só e vê a necessidade de deixar de olhar o adolescente como único responsável por seus atos. Afinal, como defende Paiva (2008) "o ato infracional é um dado 
histórico que não inicia nem termina no adolescente" (p.42), sendo necessário reconhecer também a responsabilidade de outras esferas sociais, até então esquecidas, no processo que fez o adolescente "torna-se" infrator, bem como no processo que pode favorecer sua mudança de trajetória de vida.

Com o intuito de aprofundar a compreensão sobre as concepções de responsabilização compartilhadas por operadores do sistema socioeducativo atuantes em diferentes regiões do Brasil, foi realizada uma pesquisa de natureza quali-quantitativa, cujos resultados serão apresentados a seguir.

\section{0 estudo empírico}

A coleta de dados ocorreu por meio de um questionário, do tipo escala Likert de cinco pontos, que foi aplicado online a 327 operadores do sistema socioeducativo de diferentes estados brasileiros. Incluíam-se na categoria de operadores representantes de todos os grupos profissionais que atuam quer no planejamento, quer na determinação e/ou execução de medidas socioeducativas impostas a adolescentes autores de ato infracional. Em suma, fizeram parte da amostra desde juízes até educadores sociais.

O questionário foi composto por 44 assertivas organizadas em cinco eixos temáticos a saber: (a) Adolescência e Desenvolvimento Humano; (b) Segurança Pública e Justiça; (c) Responsabilização e Socioeducação; (d) Trabalho Socioeducativo; (e) Práticas Utilizadas no Processo de Responsabilização. Ao final de cada eixo, foi disponibilizado um espaço para registro de observações e comentários espontâneos, que foram objeto de análise qualitativa. 0 questionário foi elaborado tendo como temas das assertivas os princípios referentes às leis e diretrizes do trabalho socioeducativo, bem como valores e crenças observadas no imaginário da sociedade brasileira sobre o adolescente que cometeu ato infracional e seu processo de responsabilização.

Para composição da amostra, foi utilizada a técnica da cadeia de informantes. A base para o envio dos primeiros questionários foi um banco de dados gerado por um curso de abrangência nacional, para formação continuada de atores do sistema socioeducativo. O curso foi realizado em 2010 pelo Centro de Estudos Avançados de Governo e Administração Pública da Universidade de Brasília (CEAG/UnB) em parceria com a Secretaria de Direitos Humanos (SDH) da Presidência da República.

Para a análise dos dados quantitativos, foi utilizada a mediana (Md) como estratégia de separação das respostas em três grupos, conforme manifestassem: concordância, discordância ou neutralidade (nem a favor nem contra) em relação às assertivas. Desse modo, 
utilizou-se a Md como medida de resumo das respostas e o ponto médio da escala (três) como valor neutro.

Já para a análise qualitativa dos comentários espontâneos, utilizou-se como orientação metodológica a análise do Discurso do Sujeito Coletivo (DSC), técnica que permite, por meio do método científico, conhecer pensamentos, crenças e valores de uma coletividade sobre um determinado tema (Figueiredo, Chiari, \& Goulart, 2013). Essa técnica foi desenvolvida na década de 1990 pelos pesquisadores Lefevre e Lefevre e consiste na elaboração de um discurso-síntese construído por meio da junção de partes de discursos de sujeitos diferentes.

Vale sinalizar que os resultados e discursões que serão apresentados neste artigo referem-se exclusivamente às respostas relacionadas ao eixo três, intitulado Responsabilização e Socioeducação.

\section{Resultados}

Responderam ao instrumento 327 operadores do sistema socioeducativo, sendo: 301 , do sistema de execução de medidas socioeducativas e 26 do sistema de justiça. Do total, 141 emitiram comentários espontâneos em pelo menos um dos eixos, média de 2,63 comentários por participante.

A apresentação dos resultados se dará quantitativamente, sob a forma de gráfico das medianas obtidas nos itens da escala Likert; já os resultados qualitativos serão apresentados sob a forma de Discursos do Sujeito Coletivo (DSC).

As assertivas abordadas no eixo, bem como os níveis de concordância e discordância demonstrados pelos participantes, estão representadas na figura 1. 


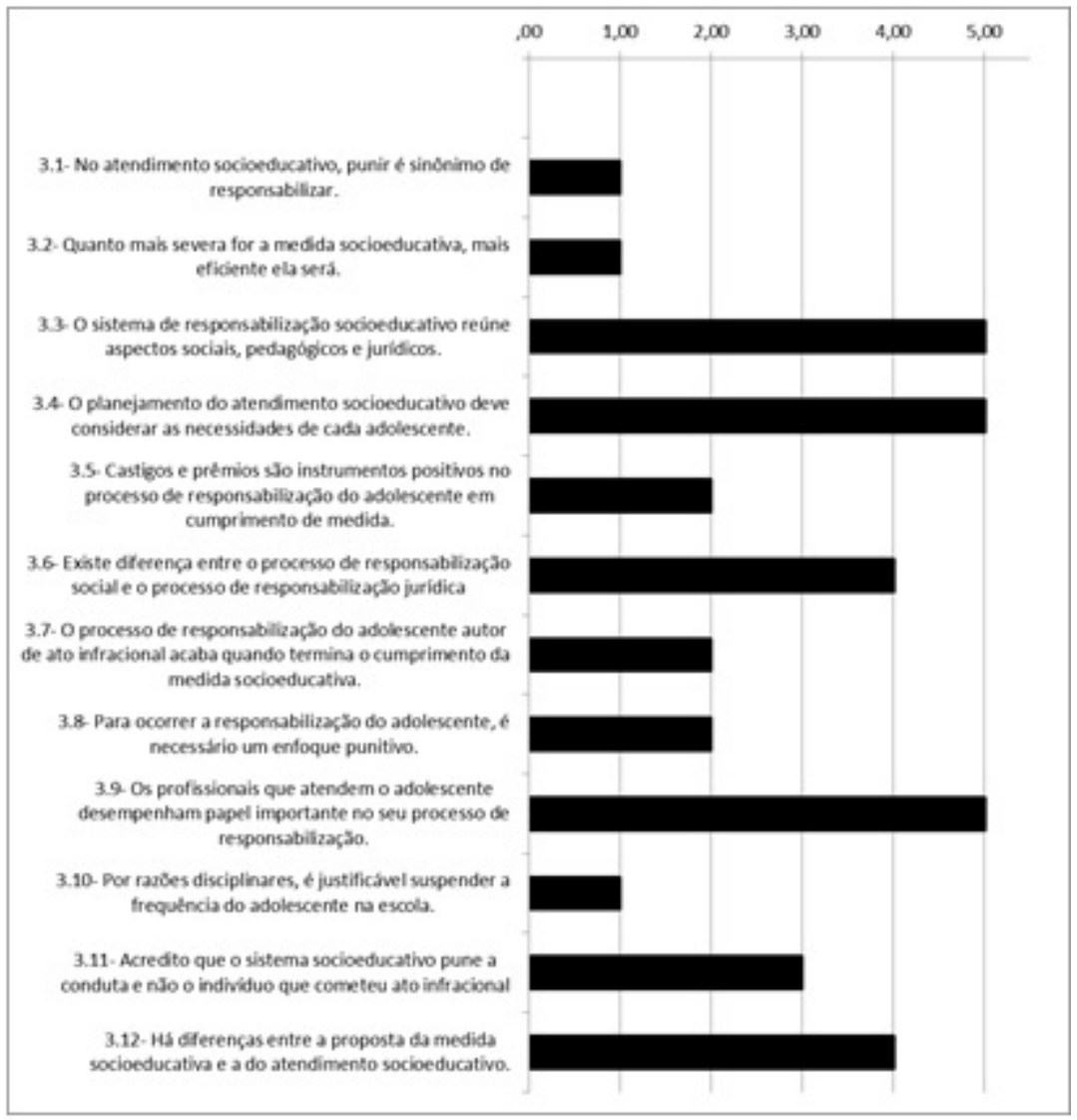

Figura l-Medianas das respostas dos participantes.

O eixo três do questionário tinha o intuito de verificar como os respondentes se posicionavam sobre o trinômio: responsabilização culpabilização - punição. De acordo com as medianas observadas no eixo, os participantes desvincularam o processo de responsabilização do adolescente de aspectos culpabilizantes e punitivos. Dessa forma, todos os itens que de alguma forma relacionavam responsabilização com punição ou culpabilização foram rejeitados pelos participantes.

Além disso, foi possível constatar que os profissionais reconheceram a diferença entre responsabilização jurídica e social e que acreditavam que o processo de responsabilização deve ir além dos aspectos meramente jurídicos, conseguindo atingir aspectos sociais e pedagógicos (item 3.3 e item 3.6). Outrossim, desvincularam o processo de responsabilização da mera determinação de uma medida a ser cumprida e reconheceram que esse processo pode ir além do tempo e dos ambientes institucionais onde a medida é posta em prática (item 3.7).

É interessante ressaltar, ainda, que, ao responderem ao item que abordava a existência de diferenças entre a medida e o atendimento socioeducativo propriamente dito (3.12), os participantes se posicionaram reafirmando tal diferença. Esse fato pode indicar que 
eles, no exercício de suas atividades profissionais, ainda não conseguem seguir as determinações e as normas socioeducativas.

Outro ponto que merece destaque entre os itens observados diz respeito à alta concordância no que se refere à necessidade de um atendimento individualizado para cada adolescente. Este fato pode indicar que os profissionais estão de acordo com a proposta do plano individual de atendimento (PIA) e, mais uma vez, reafirmam o caráter singular com que cada adolescente irá viver a sua adolescência.

O papel dos profissionais no processo de responsabilização dos adolescentes também se constituiu como um dos itens com maior índice de concordância pelos participantes. Esse evento pode servir de indicativo de que os profissionais reconhecem a sua importância para que o processo de responsabilização dos adolescentes seja de fato eficaz.

Já em relação aos comentários espontâneos dos participantes, ao ser realizada a análise das contribuições, foram encontradas quatro categorias de ideias centrais, ao ser utilizada a técnica do DSC, sendo elas: (a) a impunidade; (b) a responsabilização não punitiva; (c) a punição como meio de responsabilização; (d) as dificuldades para o processo de responsabilização socioeducativa.

Vale ressaltar que tais discursos tiveram a finalidade de demonstrar os posicionamentos dos operadores do sistema socioeducativo por meio da junção dos trechos dos comentários espontâneos que faziam referência ao mesmo tema sob a mesma perspectiva de posicionamento. Ou seja, para compor cada um dos DSCs, foi necessário que os trechos dos comentários tivessem a mesma ideia central.

\subsection{A I deia central: impunidade}

DSC 1 - O que pode ser visto é que o atendimento socioeducativo se torna paliativo e não um trabalho voltado para a efetiva resolução da questão. A chamada medida socioeducativa não tem sido efetiva tanto na prevenção de atos infracionais quanto na recuperação dos adolescentes que, muitas vezes, não se sentem punidos. Acham a medida fácil de ser cumprida, deixando o sentimento de impunidade em si e na sociedade. A falta de leis com maiores poderes de punição torna as medidas, em geral, bem mais leves que as necessárias, isso quando os jovens não são apreendidos e liberados direto da delegacia sem a aplicação de qualquer medida. Esse tipo de resposta aos atos infracionais incentiva os jovens a desafiar o "certo" esperando a inoperância do Estado no quesito responsabilização. Eles acabam rindo da impunidade e zombando dos honestos e, com isso, vão se envolvendo em atos cada vez mais graves. É engraçado que eles mesmos já usam a palavra impunidade quando se referem a isso. 


\subsection{A ideia central: responsabilização não punitiva}

DSC 2 - Punição sempre significou retribuição do mal causado, daí a utilização de práticas violentas como forma de "emendar o sujeito". No entanto, há substancial antagonismo entre reclusão, coação e medo e as possibilidades de realização do processo de formação de personalidade livre e responsável nos jovens. Acredito que a responsabilização envolva práticas de atendimento de cunho pedagógico, o que requer profissionais qualificados e aptos para atuar em contexto de garantia de direitos e responsabilização cidadã, afinal punição não gera aprendizado. Punição só funciona perante o agente punidor. Não podemos punir para depois educar, precisamos ser educadores buscando cada dia, dentro do universo do adolescente, uma nova forma de acessá-lo sem ferir sua dignidade. Dessa forma, as medidas socioeducativas possuem proposta político-pedagógica específica e clara constituída sob a matriz filosófico-legal que consubstancia o que sejam ações socioeducativas por excelência.

\subsection{A ideia central: punição como meio de responsabilização}

DSC 3 - Defendo o enfoque punitivo para o processo socioeducativo. É preciso mudar o sistema de responsabilização, dando caráter retributivo para a medida socioeducativa. Também determinar prazo de internação e não deixar à mercê de reavaliações de período de internação. Afinal, quando cometemos uma infração de trânsito somos punidos como regra. Atos contra a vida devem seguir o mesmo caminho. Não concordo nunca com um adolescente de 17 anos que mata de tocaia alguém por causa de discussão em bar, ficar apreendido 44 dias e sair pela porta da frente liberado pela juíza. A linguagem do jovem autor de ato infracional é violenta e muitas vezes sua compreensão limita-se a soluções punitivas. Dessa forma, o adolescente começa a ser punido aos 12 anos de idade e deve encarar a medida como punição para que haja o caráter da prevenção aos atos infracionais e sirva para conscientização do jovem. Caso a medida seja encarada de outra forma, traz a sensação de impunidade, como a que acontece quando os adolescentes recebem medidas de meio aberto e as encaram como remissão, perdão, absolvição e acabam também não sendo responsabilizados.

\subsection{I deia central: as dificuldades para 0 processo de responsabilização}

DSC 4 - Enfrentamos um cotidiano em que profissionais buscam nas medidas socioeducativas um meio de participar da vingança social instalada no imaginário dos que aceitaram as teses de 
desresponsabilização dos adolescentes. Não querem, com isso, a socialização, mas a punição. Além disso, presenciamos o desconhecimento e ineficácia da aplicabilidade legal por parte de alguns juristas e a dificuldade na formalização de atendimento em rede e interdisciplinar. Na maioria das vezes, o atendimento é fragmentado, voltado somente ao adolescente e pouco interventivo nos demais espaços ocupados por ele. Faltam, com isso, políticas públicas que intervenham de modo eficaz junto à família, à escola, às UBSs e à comunidade. Entendo que o adolescente considerar a medida de internação como punição seja normal, entretanto os profissionais deveriam conseguir estimular e motivar o jovem para que ele entenda o caráter educativo da medida. No entanto, muitos desses profissionais acabam reforçando tal visão. Não há esforço dos dirigentes para qualificar as equipes, o que dificulta a possibilidade de mudança ideológica. A lógica é punitiva e quem dirige as unidades são os agentes de segurança que não possuem formação pedagógica. Sem falar na sociedade que quer os adolescentes bem guardados e longe do convívio social.

\section{Discussão}

Pela análise cruzada das avaliações dos itens da escala Likert e dos Discursos do Sujeito Coletivo (DSC) apresentados, foi possível perceber que os operadores do sistema socioeducativo conhecem os princípios éticos e as bases legais do processo de responsabilização não punitivo para os adolescentes atendidos. Pode-se destacar, por exemplo, nos itens Likert 3.1 e 3.2 (ver Figura 1) a rejeição à vinculação da punição como principal estratégia para a responsabilização dos jovens. A desvinculação entre a punição e a responsabilização também pôde ser observada como núcleo de dois dos DSC apresentados anteriormente, intitulados: (a) a responsabilização não punitiva, e (b) as dificuldades para o processo de responsabilização.

Por meio desses discursos, foram apresentadas perspectivas de responsabilização condizentes com as determinações do ECA e do SINASE, demonstrando que os respondentes detêm conhecimento sobre o tema da responsabilização e aprofundamento a respeito das normas e diretrizes que regem 0 trabalho socioeducativo. Os operadores do sistema socioeducativo defenderam a necessidade de foco pedagógico para que o processo de responsabilização vá além da questão jurídica, constituindo-se como responsabilização cidadã.

Além do exposto, também foi evidenciada a concordância com a necessidade de atendimento que vise às particularidades de cada adolescente (item 3.4) e destacada a importância dos profissionais para que o processo de responsabilização seja de fato eficiente. E, 
Em particular, a questão do papel crucial dos profissionais na prática do trabalho socioeducativo foi abordada em quase todos os DSC (DSC 2, DSC 3 e DSC 4); eles demonstraram, principalmente, a necessidade de capacitação e qualificação para os profissionais.

No entanto, nem todos os DSCs defenderam a proposta de um atendimento pedagógico para os adolescentes. Foram observados posicionamentos que, apesar de demonstrarem conhecimento sobre a determinação da separação entre punição e responsabilização no atendimento socioeducativo, evidenciavam insatisfação em relação aos efeitos práticos dessa separação. De acordo com tais posicionamentos, a forma como o processo de responsabilização dos adolescentes ocorre atualmente favorece a percepção de impunidade, pela sociedade e também pelos adolescentes. Por isso, ao levar-se em consideração os DSC 1 e DSC 3 os profissionais demonstraram simpatia com a proposta de atendimento mais punitivo como meio de combate à infração, principalmente em casos de atentados contra a vida.

Por meio desse posicionamento, os operadores do sistema socioeducativo destacam a importância do enfoque punitivo para que o adolescente consiga perceber o caráter nocivo de seus atos. Esses discursos, em certa medida, contrariaram o teor observado no DSC 2 e no item 3.1 da escala Likert, visto que, nesse item, os participantes haviam discordado parcialmente da necessidade de enfoque punitivo para que o processo de responsabilização acontecesse.

Ao analisar o último item da escala Likert (3.12) em relação ao quarto DSC foi possível perceber, de modo mais claro, porque houve concordância dos respondentes sobre a diferença entre o que se visa com a medida socioeducativa e com o atendimento socioeducativo. Os discursos coletivos dos operadores do sistema revelaram problemas graves em relação à dinâmica dos trabalhos nas unidades, enfatizando a fragilidade dos atendimentos em rede e da interdisciplinaridade dentro e entre os serviços. Também relataram que, na maioria das vezes, o atendimento tem foco exclusivo no adolescente, excluindo os ambientes ocupados por ele e, com isso, sua rede de apoio.

Pelo que foi demonstrado até então, os profissionais evidenciaram ter bom domínio das diretrizes do trabalho, só que, assim como é visto na sociedade em geral, uma parcela deles tem ressalvas sobre a possibilidade de se atingir uma responsabilização eficaz sem recorrer a práticas punitivas.

O caráter espontâneo dos comentários que constituíram os DSC é algo que deve ser valorizado, visto que demonstram de forma genuína as representações dos operadores do sistema socioeducativo sobre os conteúdos abordados no questionário. Além disso, eles serviram para aprofundar a discussão, mostrando as representações dos respondentes enunciadas com suas próprias palavras. Desse 
modo, os diferentes posicionamentos observados nos DSCs são representações das concepções e crenças que 0 trabalho socioeducativo tem gerado nos seus operadores.

Também é possível observar, por meio dos diferentes DSCs, o dialogismo e a polifonia que eles apresentam (Bakhtin, 1992), sendo visíveis as trocas de informações entre aqueles discursos que são favoráveis e contrários ao processo de responsabilização punitivo e não punitivo. Desse modo, mesmo quando o processo de responsabilização não punitivo é defendido, o discurso da punição comparece e, com ele, a defesa da responsabilização punitiva.

Por isso, o confronto e o conflito observado nos vários DSCs criados encontram no diálogo a possibilidade de reconstrução de posicionamentos, os quais são (re)significados e (re)definidos pelo confronto entre vozes. Dessa forma, nenhum discurso consegue ser criado por si. Discursos são embasados em falas, ideologias, valores, pelos quais eles estarão delimitando seu ponto de vista e sua concepção de mundo.

Contudo, é importante observar que, ao contrário do que se percebia em tempos anteriores, quando o discurso da responsabilidade assentava-se exclusivamente na atribuição de culpa, hoje, outras concepções já começam a fazer parte do discurso dos operadores do sistema socioeducativo. Como todo confronto discursivo, o que se observa é a mútua modificação deles, onde nem o primeiro será totalmente aceito pelos sujeitos, nem o segundo. Por isso, só o fato de se discutir a adoção de uma nova metodologia, menos punitiva, nos processos de responsabilização, já irá interferir, gerando dúvidas sobre o processo de responsabilização e possibilitando as mudanças de crenças e práticas dentro do sistema.

\section{Conclusão}

Com a utilização das duas estratégias de coleta e análise dos dados, foi possível perceber posicionamentos complexos e menos arbitrários sobre o tema abordado na pesquisa. As opiniões expressas pelos itens Likert puderam ser complementadas e aprofundadas pelos posicionamentos, crenças e valores construídos pelos DSCs. Desse modo, pode-se ter melhor compreensão sobre o fenômeno da responsabilização dos adolescentes que cometeram atos infracionais na visão dos operadores do sistema socioeducativo.

Também foi possível perceber de modo inequívoco que o sistema socioeducativo aparece como microcosmo da sociedade, no qual posicionamentos compatíveis com aqueles frequentes no cotidiano do senso comum, e que associam a impunidade e a falta de leis mais rígidas e até retributivas, continuam sendo defendidas. No entanto, por intermédio desse estudo, pode-se observar que tal defesa tem 
maior relação com as ideologias que seguem se fazendo presentes no sistema socioeducativo do que com a falta de conhecimento sobre as normas que regem o serviço.

Dessa forma, tentou-se aqui problematizar o conceito de responsabilização a partir dos documentos normativos e do ponto de vista dos próprios operadores do sistema socioeducativo. Os resultados do estudo levaram a indicadores de desenvolvimento profissional entre os atores do sistema representados pelos participantes da pesquisa, em direção a posicionamentos mais éticos, marcados pela desvinculação entre responsabilização e práticas punitivas, algo que era recorrente entre as críticas observadas ao sistema socioeducativo. No entanto, a discussão sobre as diferentes formas de responsabilização e as suas aplicabilidades (a exemplo das que foram discutidas na parte inicial deste trabalho) ainda aparecem como ponto nebuloso para os profissionais: um único comentário fez referência a estratégias de promoção de responsabilização cidadã, como por ele foi chamado.

Esse evento indica que, apesar de claros progressos terem sido observados, ainda há muito que ser realizado para que o sistema consiga, de fato, colocar em prática um processo de responsabilização não punitivo. É a responsabilização punitiva aquela que ainda se sabe fazer, as não punitivas precisam ser pensadas, avaliadas, testadas e tudo isso requer compromisso e participação, tanto dos profissionais quanto do próprio sistema socioeducativo como um todo.

\section{Referências}

Aguinsky, B. (2007). Projeto Justiça para o século 21. Prêmio Innnovare. Porto Alegre.

Aguinsky, B. \& Capitão, L. (2008). Violência e socioeducação: Uma interpelação ética a partir de contribuições da Justiça Restaurativa. Revista Katálysis, 11(2), 257-264. Disponível em <http://www. scielo.br/pdf/rk/v11n2/11.pdf>.

Bakhtin, M. M. (2010). Para uma filosofia do ato. (V. Miotello \& C. A. Faraco). São Carlos: Pedro \& João Editores.

Brasil. Secretaria Especial de Direitos Humanos da Presidência da República. (2004). Estatuto da criança e do adolescente (Lei $\mathrm{n}$ o 8.069/90). SEDH, Brasília.

Brasil. Presidência da República. Secretaria Especial dos Direitos Humanos. Conselho Nacional dos Direitos da Criança e do Adolescente. (2012). Sistema Nacional de Atendimento Socioeducativo - SINASE. CONANDA, Brasília-DF. 
Brasil. Presidência da República. Secretaria de Direitos Humanos. (2013). Plano Nacional de Atendimento socioeducativo: Diretrizes e eixos operativos para o SINASE. SDH, Brasília.

Brayner de Farias, A. (2012). Por que a responsabilidade? - why responsibility? Conjectura: filosofia e educação, 17(1).

Diário Oficial da União (1990). Estatuto da Criança e do Adolescente. Lei no 8.069, de 13 de julho de 1990. Brasília, DF: Palácio do Planalto.

Figueiredo, M., Chiari, B. \& Goulart, B. (2013). Discurso do Sujeito Coletivo: uma breve introdução à ferramenta de pesquisa qualiquantitativa. Distúrbio de Comunicação, 25(1).

Flick, U. (2009). Introdução à pesquisa qualitativa. São Paulo: Artmed.

Frasseto, F. A. (2006). Execução da Medida Sócio-Educativa de Internação: Primeiras Linhas de uma Crítica Garantista. In ILANUD, ABMP, SEDH e UNFPA (Orgs.), Justiça Adolescente e Ato Infracional: Socioeducação e responsabilização (pp. 303341). São Paulo: ILANUD.

Lefevre, F. \& Lefevre, A. (2003) O discurso do sujeito coletivo: um novo enfoque em pesquisa qualitativa. Caxias do Sul: Educs.

Lefevre, F. \& Lefevre, A. (2006). O sujeito coletivo que fala. Comunic, 10(20), 517-24.

Meneses, R. \& Reis, A. (2009). Responsabilidade em Kanti e em Lévinas: Entre os conceitos e os fundamentos. Ágora Filosófica, 2, 103-125.

Nicodemos, C. (2006). A natureza do sistema de responsabilização do adolescente autor de ato infracional. In ILANUD, ABMP, SEDH e UNFPA (Orgs.), Justiça Adolescente e Ato Infracional: Socioeducação e responsabilização (pp. 62-85). São Paulo: ILANUD.

Paiva, I. (2008). Reconstruindo histórias: vivências de adolescentes em liberdade assistida na comarca de Muriaé-MG. Dissertação de mestrado. Pontifícia Universidade Católica, Rio de Janeiro, RJ, Brasil.

Ramidoff, M. L. (2011). Lições de direito da criança e do adolescente: ato infracional e medidas socioeducativas. Curitiba: Juruá.

Sifuentes, T., Dessen, M. \& Lopes de Oliveira, M. (2007). Desenvolvimento humano: desafios para a compreensão das trajetórias probabilísticas. Psicologia: Teoria e Pesquisa, 23(4), 379-385. Disponível em <http://www.scielo.br/scielo.php?script=sci_arttext\&pid=S010 2-37722007000400003\&lng=pt\&tIng=pt.

10.1590/S0102$37722007000400003>$

Sobral, A. (2009). O conceito de ato ético de Bakhtin e a responsabilidade moral do sujeito. Revista eletrônica Bioéticos, Centro Universitário São Camilo, 3(1), 121-126. 
Vicentin, M. C. (2006). A questão da responsabilidade penal juvenil: notas para uma perspectiva ético-política. In ILANUD, ABMP, SEDH e UNFPA (Eds.), Justiça Adolescente e Ato Infracional: Socioeducação e responsabilização (pp. 151-173). São Paulo: ILANUD.

Vicentin, M. C., Catão, A., Borghi, A. \& Rosa, M. (2012). Adolescência e sistema de justiça: problematizações em torno da responsabilização em contextos de vulnerabilidade social. Responsabilidades, 1(2), 271-295.

\section{Endereço para correspondência \\ Fernanda Pinheiro Rebouças Valente}

Universidade de Brasília

Instituto de Psicologia - Departamento de Psicologia Escolar e do Desenvolvimento

Campus Darcy Ribeiro - ICC Sul, sala A1-010, Asa Norte, CEP 70910-900, Brasília DF, Brasil

Endereço eletrônico: fernandareboucas@hotmail.com

\section{Maria Cláudia Santos Lopes de Oliveira}

Universidade de Brasília

Instituto de Psicologia - Departamento de Psicologia Escolar e do Desenvolvimento

Campus Darcy Ribeiro - ICC Sul, sala A1-010, Asa Norte, CEP 70910-900, Brasília DF, Brasil

Endereço eletrônico: mcsloliveira@gmail.com

Recebido em: 19/02/2015

Reformulado em: 13/08/2015

Aceito para publicação em: 03/09/2015

\section{Notas}

* Graduada em Psicologia pela Universidade Federal do Rio Grande do Norte (UFRN) e Mestre em Processos de Desenvolvimento Humano e Saúde pelo Instituto de Psicologia da Universidade de Brasília (UnB).

** Doutora em Educação pela Pontifícia Universidade Católica do Rio de Janeiro (PUCRJ); Professora do Departamento de Psicologia Escolar e do Desenvolvimento e do Programa de Pós-graduação em Processos de Desenvolvimento Humano e Saúde da Universidade de Brasília (UnB). Pesquisadora do Laboratório de Microgênese das Interações Sociais (LABMIS) da Universidade de Brasília (UnB). 